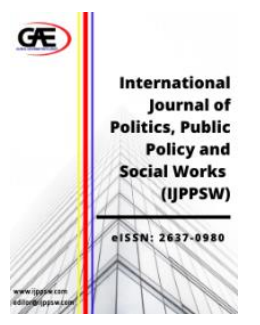

\author{
INTERNATIONAL JOURNAL OF \\ POLITICS, PUBLICS POLICY \\ AND SOCIAL WORKS \\ (IJPPSW) \\ www.ijppsw.com
}

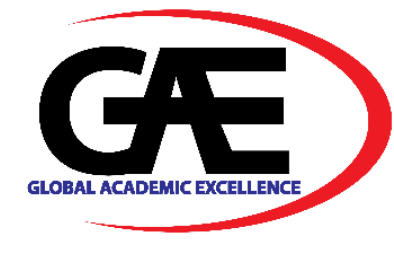

\title{
INCREASING THRIVING AT WORK THROUGH WORKPLACE SPIRITUALITY AMONG GOVERNMENT SERVANT IN PENANG, MALAYSIA
}

\author{
Zulaiha Ahmad ${ }^{1 *}$, Nurwahida Fuad ${ }^{2}$, Muhammad Faiz Noor Ramlee ${ }^{3}$, Ahmad Nizan Mat Noor ${ }^{4}$, \\ Syazwani $\mathrm{Ya}^{5}$ \\ 1 Faculty of Business and Management, Universiti Teknologi MARA (UiTM), Perlis Branch, Malaysia \\ Email: zulaiha895@uitm.edu.my \\ 2 Faculty of Business and Management, Universiti Teknologi MARA (UiTM), Perlis Branch, Malaysia \\ Email: wahida.fuad@uitm.edu.my \\ 3 Faculty of Business and Management, Universiti Teknologi MARA (UiTM), Perlis Branch, Malaysia \\ Email: faiznor24@gmail.com \\ 4 Faculty of Business and Management, Universiti Teknologi MARA (UiTM), Perlis Branch, Malaysia \\ Email: ahmadnizan@uitm.edu.my \\ 5 Faculty of Business and Management, Universiti Teknologi MARA (UiTM), Perlis Branch, Malaysia \\ Email: syazwani446@uitm.edu.my \\ Corresponding Author
}

\section{Article Info:}

\section{Article history:}

Received date: 17.12 .2020

Revised date: 24.01 .2021

Accepted date: 02.02 .2021

Published date: 01.03.2021

\section{To cite this document:}

Ahmad, Z., Fuad, N., Ramlee, M. F. N., Mat Noor, A. N., \& Ya, S. (2021). Increasing Thriving At Work Through Workplace Spirituality Among Government Servant in Penang, Malaysia. International Journal of Politics, Publics Policy and Social Works, 3 (8), 01-12.

DOI: $10.35631 /$ IJPPSW.38001.

\begin{abstract}
:
Creating sustainable performance emerged as a crucial issue for any profit and non-profit organization. In this complex and competitive environment, organizations should play a better role in encouraging their employees to thrive at work. Existing evidence from various industries confirmed that thriving at work contributed to organizational performance and helps to mitigate problems such as stress and turnover. This study relied on the socially embedded model to unravel the connection between meaningful work, sense of community, organizational values, and thriving at work. Survey data were gathered from government officers attached from four local government institutions in Malaysia. The analysis employed in the study were Descriptive, Pearson correlation, and Multiple Regression. The study found that thriving positively relates to meaningful work. However, the results surprisingly revealed that a sense of community and organizational values were not significantly related to thriving at work. Interpretations of results, implications, and future research are discussed. Thus, this study will benefit organizations as well as academic researchers.
\end{abstract}




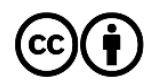

Keywords:

Thriving, Meaningful Work, Sense of Community, Organizational Value, Public Sector

\section{Introduction}

Due to the complex and dynamic environment, a thriving workforce is essential in building competitive and sustainable organizational performance. According to Abid (2016) sustainability of the organizations is extremely link with the human thriving at work. It is very important for organizations to focus on human sustainability compared to economic and environmental dimensions of sustainable organizations (Spreitzer, Porath \& Gibson, 2012). Research on human thriving has received a great deal of attention and it has been rapidly grown among researchers and practitioners. Specifically, thriving can be defined as "phychological state in which individuals experience both sense of vitality (i.e., the positive feeling of having energy available that reflects individual's feelings of aliveness) and sense of learning (i.e., the sense that individual acquire and apply, knowledge and skills) at work" (Spreitzer, Sutcliffe, Dutton, Sonenshein \& Grant, 2005, p. 538).

This widespread interest of this behavior stems from the fact that thriving is indeed vital to the survival of an organization. Scholars have recognized the significant of this behavior which may benefit both individuals and organizations (Spreitzer \& Porath, 2012) and thriving at work overcomes negative work related to attitude and behavior (Anjum, Marri \& Khan, 2016). Previous scholars discovered several outcomes of thriving at work includes self-development, positive mental and physical health, better individual and organizational performance, reduce stress, contagion to others (Spreitzer \& Sutcliffe, 2007), life satisfaction (Zhai, Wang \& Weadon, 2017), productive and highly energized (Spreitzer \& Porath, 2012), reduce health care costs and absenteeism (Spreitzer et al., 2005) and thriving also spills to personal life (Spreitzer et al., 2012).

Scholars also have begun investigating spirituality with employee work attitudes such as job satisfaction, job involvement, organizational commitment, intention to quit, self-esteem (Pawar, 2009; Milliman, Czaplewski \& Ferguson, 2001; Milliman, Czaplewski \& Ferguson, 2003), work engagement and thriving at work (Walt, 2018). Although, the growing body of literature on workplace spirituality has shown an increasing number, most prior scholars have not adequately assessed the effects of workplace spirituality and thriving at work (Walt, 2018). Specifically only limited study (e.g. Walt, 2018) have been conducted to establish the relationship between workplace spirituality and thriving at work. To date, there is no research that has been conducted among Malaysians' public sector employees. Hence, this empirical study attempts to investigate the relationship of workplace spirituality and thriving at work among employees in the Malaysian public sector context.

\section{Literature Review}

\section{Thriving at Work}

Spreitzer et al. (2005) define thriving at work as a positive psychological state in which individuals experience both a sense of vitality and learning. They further suggests that those employees will regulate their own growth by feeling energized and alive at work (vitality) and 


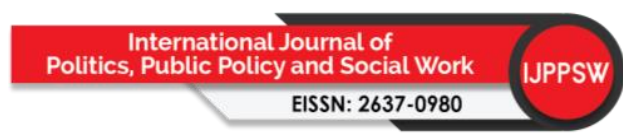

Volume 3 Issue 8 (March 2021) PP. 01-12 DOI: 10.35631/IJPPSW.38001

by having a sense of continually enhancing and applying the knowledge (learning). Based on the idea that thriving is socially embedded, Spreitzer et al. (2005) developed a theoretical model which discovered three factors namely (1) unit contextual features, (2) resources produced in doing work and (3) agentic work behaviors contribute to thriving at work. Unit contextual features reflect the way that work is accomplished such how decision are made, how information is shared and the extent to which interactions based on trust and respect. Resources produced in doing work features knowledge, positive affective resources, relational resources and positive meaning that enable individual to react in taking a certain action. Agentic work behavior described as an engine of thriving at work and are contributed by both unit contextual features and resources produced in doing of work (Spreitzer et al., 2005). There are three agentic work behaviors that contribute to thriving at work such as task focus, exploration and heedful relating.

Study conducted by Spreitzer and Porath (2012) revealed that thriving employees demonstrate $16 \%$ better performance and are less feel burnout, $32 \%$ thriving employees had higher level of organizational commitment and $46 \%$ of them feel satisfy with their job. Thus, thriving deliver an adaptive function that helps employees to move forward in one's self-development (Spreitzer et al., 2005). Thriving also has been differentiate by several constructs namely resilience, flourishing, subjective well-being and self-actualization (Spreitzer et al., 2005). Spreitzer et al. (2005) argued that thriving can occur with or without adversity. According to Wolumbwa, Muchiri, Misati, Wu, and Meliani (2017), testing a multilevel model among public servant employees in regional government agency in Indonesia revealed that servant leadership and core self-evaluations are positively related to thriving at work at different levels.

\section{Workplace Spirituality}

Workplace spirituality has been defined as "the recognition that employees have an inner life that nourishes and is nourished by meaning work that takes place in the context of community" (Ashmos \& Duchon, 2000). However, Jurkiewicz and Giacalone (2004) proposed definition of workplace spirituality as "a framework of organizational values evidenced in the culture that promote employees' experience of transcendence through the work process, facilitating their sense of being connected to others in a way that provides feelings of completeness and joy". Milliman et al. (2003) discovered three core dimensions for three levels of workplace spirituality such as meaningful work (individual level), sense of community (group level) and organization values (organization levels). This findings align with the study conducted by Neal and Bennet (2000) which suggested that there are three levels of employees' involvement in spirituality at the workplace. Cavanagh (1999) claimed that nowadays spirituality is not connected with any specific religious tradition but based on employee personal values and philosophy. Organizations which provide the employees with the opportunities to fulfil their spirituality has been proven to perform better (Konz \& Ryan, 1999).

Pawar (2008) in the study conducted among employees from the various organizations discovered that workplace spirituality particularly meaning in work, community at work and positive organizational purpose is positively associated with employees work attitudes. Previous research by Karakas (2010) claimed that workplace spirituality might support organizational performance such as enhance employee well-being and quality of life, provides sense of purpose and meaning at work and lastly provides a sense of interconnectedness among community. Spirituality also postulate a positive impact (Ashraf, Simsab, Nazish \& Farooqi, 2014; Jurkiewicz \& Giacalone, 2004), respectively organizational commitment and job Copyright $\odot$ GLOBAL ACADEMIC EXCELLENCE (M) SDN BHD - All rights reserved 
satisfaction (Pradhan, Pradhan \& Jena, 2016), innovative work behavior (Asfar \& Badir, 2017), organizational citizenship behavior (Nasurdin, Nejati \& Mei, 2013), employee engagement, intention to stay, service delivery (Milliman, Gatling \& Kim, 2018) and thriving at work (Walt, 2018). Walt (2018) in the study conducted among 259 employees working at small, medium and macro enterprises (SMMEs) located in South Africa revealed that spiritual workplaces needed to be created to promote work engagement and thriving at work. Breytenbach (2016) pointed out that the degree of employee who have spirit towards their work depend on how they feel connected and engaged at the workplace. Furthermore, it is very crucial for organization to ensure employees practice spirituality (Breytenbach, 2016) and also the organization should give more attention to create a harmonious relationship and networking among employees (Walt, 2018).

\section{Meaningful Work}

According to Dik, Byrne and Steger (2013) and Rosso (2010), meaningful work can be defined as a positive valence construct discussing the quantity that human beings involve in their work. Meaningful at work signifies how workers interrelate with their day-to-day work at the individual level. A fundamental aspect of spirituality at work involves having a deep sense of meaning and purpose in one's work. This dimension represents how individual enjoy the work, energized by work and how the work gives personal meaning to them (Milliman et al., 2003). Meaningful work derived when employee has a fully understanding regarding the nature of the task environment, feels a sense of congruence between their own values, job requirements and organizational missions and goals (Ghadi, Fernando \& Caputi, 2015). Steger, Dik and Duffy (2012) highlighted three core components of meaningful work which employee discover such as effort to have substantial and purposefulness, the influence work makes to find wider value in life and the desire for one's work to make an encouraging influence to the superior good. Rosso, Dekas and Wrzesniewski (2010) recognize four impacts of meaningful work include self (values, motivation and ideals); others (coworkers, leaders, organizations and groups); work context (design of job duties, organizational task, economic situations) and religious existence (spirituality and sacred callings). As employees, they felt their work are meaningful when they place positive qualities of work, developing own competencies to be better in resulting positive outcomes and influencing work content (Vuori, San, \& Kira, 2012). Employees seek to an experience personal meaning that would give them a sense of motivation. Hackman and Oldham (1976) claimed that there is interconnection of meaning work and personal motivation specifically they found that feedback and autonomy (meaningful work) maximizes level of internal motivation.

Hence, the hypothesis posits:

H1: Meaningful work has a positive relationship with thriving at work.

\section{Sense of Community}

Sense of community refers to perception that humans perceive themselves as link to each other and deep connection between one's internal characters of different human beings (Maynard, 1992; Miller, 1992; Ashmos \& Duchon, 2000). Similar with the word used by Duchon and Plowman (2005), it means notions of sharing, mutual obligation and commitment that connect people to each other. Strong senses of community will lead to positive impacts on productivity, efficiency, morale and entertaining workplace (Glew \& Russell, 2013). Furthermore, sense of community encourages personal achievement (Pretty et al., 1996), increases the value of work Copyright (C) GLOBAL ACADEMIC EXCELLENCE (M) SDN BHD - All rights reserved 


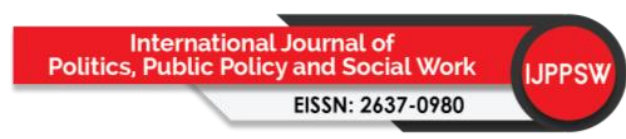

Volume 3 Issue 8 (March 2021) PP. 01-12 DOI: 10.35631/IJPPSW.38001

(McGinty, Justice, \& Rimm-Kaufman, 2008) and built self-confidence and growing independence (McKenna \& Newton, 2008). Ashmos and Duchon (2000) discovered it is required for employees to experience part of community as it will reflect human experience and human well-being (Scannel \& Gifford, 2017). Other scholars have introduced alternative constructs that overlap with the concept of sense of community such as place attachment (Scannel \& Gifford, 2010) and social support (Joe-Akunne, Etodike, \& Okonkwo, 2019; Fenney \& Collins, 2015). Scannel and Gifford (2010) identified three dimensions of place attachment; a) a person's use of individually or collectively b) the place's geographical scale and physical characteristics and c) psychological processes that comprise the bond (affect, cognition and behaviour).

A study conducted among newly employed workers at universities in Nigeria by Joe-Akunne et al., (2019) found that family, friends and others' support were the predictors of thriving at work. Feeney and Collins (2015) also agreed that close and caring relationship would effect on thriving at work. They further highlighted that people may potentially thrive through two life context (coping with life's adversities and actively pursuing life opportunities for growth and development). Moreover, Spreitzer et al., (2005) believed that thriving takes place through social interactions that bond individuals together within inside and outside organization while doing work, talking about work and observing others doing their work. When individuals feel a spirit, friendly work environment and feel part of a community, they will have long term effects on thriving at work place.

Hence, the hypothesis posits:

$\mathrm{H} 2$ : Sense of community has a positive relationship with thriving at work.

\section{Organizational Values}

Values are the key aspect of organizational culture and leadership that impact both individual and organizational performance (Posner, 2010; Wambugu, 2014). Organizational values is described as a person's belief that superiors and workers in the organization have applicable values, a solid sense of right and wrong and concerned about the well-being of its personnel and community (Ashmos \& Duchon, 2000). It also refers to a strong experience of alignment among their individual morals and the organization's mission. The achievement and constant performance of organizations is linked to the join values of their employees (Zhang, Austin, Glass, \& Mills, 2008). Evidence has proven that followers internalize organizational values when they distinguish that their leaders are practicing behaviours related with supported core values (Hannah, Schaubroeck \& Peng, 2016). Thus, it can be said that organizational values play a vital role since it have a significant impact on stakeholders as well as organizational process and outcomes (Watson, Papamarcos \& Bean, 2004). According to Spreitzer et al., (2005), work environment, specifically organizational culture characterized by a climate of thrust and respect promotes thriving at workplace. Such feeling may encourage sharing of information and learning behaviours that enable individual and organizational growth and development. However, Wambugu (2014), in the study conducted among all employees in various sectors at Kenya revealed that organizational value has a minimal influence to employee performance. 
Hence, the hypothesis posits:

H3: Organizational values has a positive relationship with thriving at work.

\section{Methodology}

This study's population was on 115 employees work as government officer from four department namely Development, Management Services, Land Management and Guide and lastly Department Policies. In this study, stratified sampling was employed. This technique means that process of stratification or segregation, followed by random selection of subjects from each stratum. The population was divided into mutually exclusive groups which are relevant, appropriate and meaningful with the context of the study. According to Krejcie and Morgan (1970), the sample size of 86 was considered applicable according to the rule of thumb. However, researcher decided to collect 115 questionnaires due to small population.

A quantitative method, i.e self-administered questionnaires were distributed to government officer in four government institutions located in Penang. The researchers received approval from the top management in distributing questionnaire. Respondents were informed the objective of the research whereby questionnaires were distributed by approaching each of officer to participate and answering the survey. Out of 115 questionnaires distributed, all 115 questionnaires were returned and usable for data analysis. Data collection was successfully completed in two weeks. The contents were organized based on the measures of independent, dependent as well as demographic questions seeking respondent's information. The independent variable of the present study were meaningful work, sense of community and organizational values and the dependent variable was thriving at work. Each respondent's response were computed and saved. In order to perform quantitative analysis, the data were analyzed using SPSS Version 25. Bivariate correlation was used to test the relationship between meaningful work, sense of community, organizational values and thriving at work. Correlation coefficient reveals the direction of relationship between variables. Hierarchical multiple regression was utilized to test the main effect of meaningful work, sense of community and organizational values in predicting thriving at work.

All independent variable (meaningful work, sense of community and organizational values) were assessed from scales developed by Milliman et al. (2003). Overall, there were 32 items measuring independent variables using five-point Likert scales ranging from strongly disagree (1) to strongly agree (5). Sample items for meaningful work are: "I enjoy my work and I understand what gives my work personal meaning". Items for sense of community such as "I am part of community" and items for organizational values such as "I feel connected with the mission of the organization". Ten items for thriving at work were assessed using the scales developed by Porath et al. (2012) and lastly, five items related to the demographic profile of the respondents such as gender, age, marital status, working experience and level of education.

\section{Results and Discussion}

Based on Table 1, the total of 115 respondents comprised of $53 \%$ were male, while $47 \%$ were female. Most of the respondents were married (88.7\%) and have experience working from 11 to 15 years. With the most of the range of age between 30 to 39 years old, most of them have education experience from secondary school. 
Table 1: Respondents Profile

\begin{tabular}{llcc}
\hline Variable & Category & Frequency & \% \\
\hline Gender & Male & 61 & 53.0 \\
& Female & 54 & 47.0 \\
\hline Age & $20-29$ & 11 & 9.6 \\
(years old) & $30-39$ & 66 & 57.4 \\
& $40-49$ & 28 & 24.3 \\
& $50-59$ & 7 & 6.1 \\
& 60 above & 3 & 2.6 \\
\hline Marital Status Single & 13 & 11.3 \\
& Married & 102 & 88.7 \\
\hline Education & Secondary School/ & 68 & 59.1 \\
& Certificate & & \\
& Undergraduates & 16 & 13.9 \\
& Postgraduates & 19 & 16.5 \\
& Others & 11 & 9.6 \\
& No Answer & 1 & 0.9 \\
\hline Tenure & Less than a year & 5 & 4.3 \\
& $1-5$ & 11 & 9.6 \\
& $6-10$ & 30 & 26.1 \\
& $11-15$ & 38 & 33.0 \\
& $16-20$ & 12 & 10.4 \\
& $21-25$ & 10 & 8.7 \\
& Above 26 & 9 & 7.8 \\
\hline
\end{tabular}

The Cronbach-alpha for each variable is presented in Table 2. The results of the items used in the study are reliable suggested by Nunnally (1978). The Cronbach alpha range from .800 to .905. Referring the above table, the value Cronbach alpha for meaningful of work and sense of community considered good, organizational values was considered as excellent and thriving at work considered as acceptable.

Table 2: Cronbach Alpha for Each Variables

\begin{tabular}{lcc}
\hline \multicolumn{1}{c}{ Variables } & $\begin{array}{c}\text { Number of } \\
\text { Items }\end{array}$ & Alpha \\
\hline Meaningful work & 5 & .800 \\
Sense of community & 5 & .823 \\
Organizational values & 7 & .846 \\
Thriving at work & 10 & .905 \\
\hline
\end{tabular}




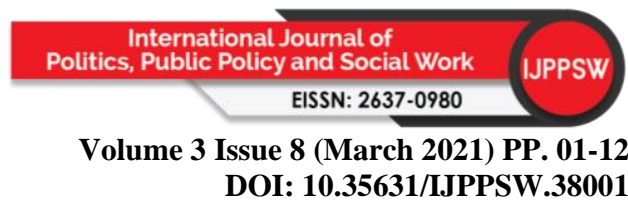

The descriptive statistics and intercorrelations of the variables are presented in Table 3. All variables were tapped on a five-point scale range from strongly disagree (1) to strongly agree (5). It can be seen that the mean on all variables shows that it was relatively high, with the mean score of all variables ranged from 3.94 to 4.16 which exceed the scale midpoint of 3 . This indicated that majority of respondents agreed and believed meaningful, sense of community and organizational values will influence on how staffs feel about thriving at work.

The initial relationship between meaningful work, sense of community and organizational values with thriving at work was investigated using Pearson correlations coefficient. Based on the findings, there was a moderate positive correlation between meaningful and thriving at work $(\mathrm{r}=0.534, \mathrm{P}<0.00)$. While sense of community $(\mathrm{r}=0.324, \mathrm{P}<0.01)$ and organizational values was $(r=0.293, P<0.02)$ were significantly low positive correlation related with thriving at work. A summary of the means, standards deviations and correlations are provided in Table 3.

Table 3: Correlation Analysis

\begin{tabular}{lcccccc}
\hline & Mean & SD & MW & SC & OV & TW \\
\hline Meaningful Work (MW) & 4.12 & 0.513 & 1 & & & \\
Sense of Community (SC) & 4.15 & 0.527 & $0.585^{* *}$ & 1 & & \\
Organizational Values (OV) & 3.94 & 0.555 & $0.604^{* *}$ & $0.665^{* *}$ & 1 & \\
Thriving at work (TW) & 4.15 & 0.442 & $0.534^{* *}$ & $0.324^{* *}$ & $0.293^{* *}$ & 1 \\
\hline
\end{tabular}

The hierarchical multiple regression analysis was carried out to test whether meaningful work, sense of community and organizational values influence thrive at work among Malaysian government officers. Based on Table 4 , the present study found that meaningful work $(\beta=.536$, $\mathrm{p}<.01)$ was significantly contributed to the prediction of thriving at work. However, sense of community $(\beta=.056, \mathrm{n} . \mathrm{s})$ and organizational values $(\beta=-.058$, n.s $)$ were not significant predictors to thrive at work. Overall, the variance explained by the set of predictors is $26.7 \%$. Hence, only $\mathrm{H} 1$ was supported while $\mathrm{H} 2$ and $\mathrm{H} 3$ were rejected.

The result revealed that meaningful influence employees thriving at work. This finding is further supported by other research (Kira \& Balkin, 2014; Judge, 2019; Pawar, 2008), which also proved that meaningful work significantly contributed to predicting thriving at work. It shows that meaningful work is crucial in inspiring employees to always continually learning at work by seeking new knowledge and skills. Perhaps, meaningful work also is discovered vital to encourage employees' passionate, excitement and energetic towards their task given.

However, results reveal that sense of community is not significantly contributed to the prediction of thriving at work. This finding is not consistent to the Socially Embedded Model of Thriving at Work (Spreitzer et al., 2005) whereby the scholar highlighted that thriving occurs through social interaction with others while doing work, talking about work and observing others doing their work. The study is also aligned with previous study by Gerbasi, Porath, Parker, Spreitzer, and Cross, (2017) whereby the study found that individuals who are thriving at work are less susceptible to the effects of negative relationships (de-energizing) that may affect job performance. Collins (2014) also revealed that non-work related factor such as social support from families and friends would not affect thriving at the work place. The current result Copyright $\odot$ GLOBAL ACADEMIC EXCELLENCE (M) SDN BHD - All rights reserved 


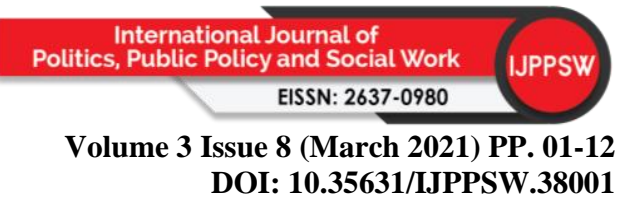

is contradicted with the study conducted by a few studies before (Feeney \& Collins, 2015; JoeAkunne, 2019). Finally, result also revealed that organizational values has no link to thriving at work. The result is not aligned with the study conducted by Wambugu (2014) which discovered organizational value has more significant affect on employee's performance compare to organizational climate.

Table 4: Multiple Regression Results

\begin{tabular}{lccc}
\hline Variables & B & $\boldsymbol{T}$ & Sig. \\
\hline Meaningful Work & 0.536 & 4.874 & 0.000 \\
Sense of Community & 0.056 & 0.467 & 0.641 \\
Organizational Values & -0.058 & -0.487 & 0.628 \\
\hline R Square & 0.288 & & \\
Adjusted R Square & 0.267 & & \\
F Value & 13.728 & & \\
& & & \\
Dependent Variable : Thriving at Work & & & \\
\hline
\end{tabular}

\section{Conclusion}

The main objective of this study is to examine the relationship between workplace spirituality namely meaningful work, sense of community and organizational values in relation to thriving at work among public sector servant located at Penang, Malaysia. As we all know workplace spirituality might be a predictor of employee work attitudes. Based on the result, it was found out that only meaningful work was significantly related to thriving at work. The result conveyed that what employer should do in order to increase employees' wellbeing and also to provide better support for all employees to remain enthusiastic in performing their job. Hence, the organization should play an important role to create meaningful work. To encourage culture of thriving at work, organizations should create compassionate working environment such as job rotation, job enrichment and job enlargement in order to promote personal and holistic growth. Furthermore, job should be carefully designed and consideration in the aspects of autonomy, skill variety and job challenge should be given to employees in order to promote meaningful work (Walt, 2018). Kira and Balkin (2014) further added that organizations can foster sustainable thriving by providing opportunities to employees to participate in seminar, coaching or training. Since the finding of the study only reported that only one significant variable towards thriving at work namely meaningful work, therefore, the study would like to suggest for the future research to use another variables and different population that may yield to other result.

\section{References}

Abid, G. (2016). How does thriving matter at workplace. International Journal of Economics and Empirical Research, 4 (9), 521-527.

Anjum, M.A., Marri, S.R., \& Khan, H. (2016). Thriving at work: Evidences from Telecom Companies in Balochistan. Gomal University Journal of Research, 32 (2), 36-46.

Ashmos, D.P. and Duchon, D. (2000), Spirituality at work: a conceptualization and measure. Journal of Management Inquiry, 9 (2), 134-145.

Ashraf, S., Simsab, A., Nazish, A., \& Farooqi, Y.A. (2014). Relationship of workplace spirituality with positive job attitude (Job satisfaction, job involvement and 


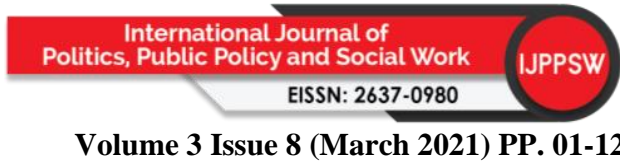

Volume 3 Issue 8 (March 2021) PP. 01-12 DOI: 10.35631/IJPPSW.38001

organizational commitment): A study of Public Sector University. International Journal of Management Sciences and Business Research, 3 (10), 96-111.

Cavanagh, G.F. (1999). Spirituality for mangers: context and critique. Journal of Organizational Change Management, 12, 186-199.

Collins, L. A. (2014). Thriving at work: Contextual versus non-contextual factors. Retrieved from http://www.library2.smu.ca/handle/01/25857\#.X1g0CnkzbIU

Dik, B.J., Byrne, Z.S., \& Steger, M.F. (2013). Purpose and meaning in the workplace. American Psychological Association.

Duchon, D., \& Plowman, D.A. (2005). Nurturing the spirit at work: Impact on work unit performance. The Leadership Quarterly, 16 (5), 807-833. doi: 10.1016/j.leaqua.2005.07.008

Feeney, B.C., \& Collins, N.L. (2015). New look at social support: A theoretical perspective on thriving through relationships. Pers Soc Psychol Rev, 19 (2), 113-147.

Gerbasi, A., Porath, C.L., Parker, A., Spreitzer, G., \& Cross, R. (2017). Destructive deenergizing relatonships: How thriving buffers their effect on performance. Journal of Applied Psychology. Retrieved from http://hdl.handle.net/10871/25562.

Ghadi, M.Y., Fernando, M., \& Caputi, P. (2015). Describing work as meaningful: towards a conceptual clarification. Journal of Organizational Effectiveness People and Performance, 2 (3), 202-223.

Glew, R. H., \& Russell, J.C. (2013). The importance of community in academic health center. Teaching and Learning in Medicine, 25 (3), 272-274.

Hackman, J.R., \& Oldham, G.R. (1976). Motivation through the design of work: test of a theory. Organizational Behavior and Human Performance, 16 (2), 250-279.

Hannah, S.T., Schaubroeck, J.M., \& Peng, A.C. (2016). Transforming followers' value internalization and role self-efficacy: Dual process promoting performance and peer norm-enforcement. Journal of Applied Psychology, 101 (2), 252-266. http://www.sajip.co.za

Joe-Akunne, C.O., Etodike, C.E., \& Okonkwo, K.I. (2019). Social dynamics in the workplace: Does social support enhance thriving of newbie employees in the private sector? Asian Journal of Advanced Research and Reports, 6 (1), 1-9.

Judge, E. (2019). The experience of thriving at work for managers in the private and public sector. Retrieved from https://eprints.lancs.ac.uk/id/eprint/141798/1/2020judgephd.pdf

Karakas, F. (2010). Spirituality and performance in organizations: A literature review. Journal of Business Ethics, 94 (1), 89-106.

Kira, M., \& Balkin, D.B. (2014). Interactions between work and identities: Thriving, withering, or redefining the self? Human Resource Management Review, 24, 131-143.

Konz, G. and Ryan, F. (1999). Maintaining an organizational spirituality: no easy task. Journal of Organizational Change Management, 12 (3), 200-210.

Maynard, H. (1992). New traditions in business: Spirit and leadership in the $21^{\text {st }}$ century. San Francisco, CA: Berret-Koehler.

McGinty, A.S., Justice, L., \& Rimm-Kaufman, S.E. (2008). Sense of school community for preschool teachers serving at-risk children (Vol. 19). Early Education and Development.

McKenna, L., \& Newton, J.M. (2008). After the graduate year: A phenomenological exploration of how new nurses develop their knowledge and skill over the first 18 months following graduation. Australian Journal of Advanced Nursing, 25 (4), 9-15.

Miller, W. (1992). How do we put our spiritual values to work? San Francisco: Berret-Koehler. 


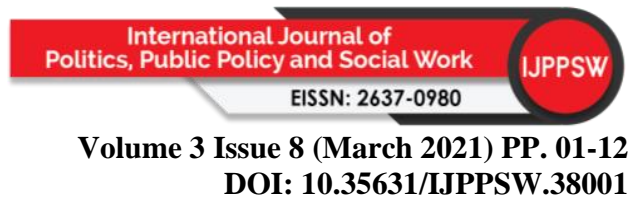

Milliman, J., Czaplewski, A. J., \& Ferguson, J. (2003). Workplace spirituality and employee work attitudes: An exploratory empirical assessment. Journal of Organizational Change Management, 16 (4), 426-447.

Milliman, J.F., Czaplewski, A.J., \& Ferguson, J.M. (2001). An exploratory empirical assessment of the relationship between spirituality and employee work attitudes. Academy of Management Proceedings, 1-7.

Neal, J.A., \& Bennet, J. (2000). Examining multi-level or holistic spiritual phenomena in the workplace. Management, Spirituality and Religion Newsletter, Academy of Management Winter, 1-2.

Nunnally, J.C. (1978). Psychometric theory. New York: McGraw-Hill.

Pawar, B.S. (2009). Individual spirituality, workplace spirituality and work attitudes: An empirical test of direct and interaction effects. Leadership and Organization Development Journal, 30 (8), 759-777.

Peterson, N.A., Speer, P.W., \& McMillan, D.W. (2008). Validation of brief sense of community scale: Confirmation of the principal theory of sense of community. Journal of Community Psychology, 36 (1), 61-73.

Porath, C., Spreitzer, G., Gibson, C., \& Garnett, F.G. (2012). Thriving at work: Toward its measurement, construct validation and theoretical refinement. Journal of Organizational Behavior, 33 (2), 250-275.

Posner, B. Z. (2010). Another look at the impact of personal and organizational values congruency. Journal of Business Ethics, 97 (4), 535-541.

Pretty, G. M., McCarthy, M.E., \& Catano, V.M. (1996). Psychological environments and burnout: Gender considerations within corporation. Journal of Organizational Behavior, 13 (1), 701-711.

Rosso, B.D., Dekas, K.H., Wrzesniewski, A. (2010). On the meaning of work: A theoretical integration and review. Research in Organizational Behavior, 30, 91-127.

Scannel, L., \& Gifford, R. (2017). The experienced psychological benefits of place attachment. Journal of Environmental Psychology, 51, 256-269.

Spreitzer, G., \& Porath, C. L. (2012). Creating sustainable performance. Harvard Business Review, 1-9

Spreitzer, G., Porath, C.L., \& Gibson, C.B. (2012). Toward human sustainability: How to enable more thriving at work? Organizational Dynamics, 41, 155-162.

Spreitzer, G., Sutcliffe, K., Dutton, J., Sonenshein, S., \& Grant, A.M. (2005). A socially embedded model of thriving at work. Organization Science, 16 (5), 537-549.

Spreitzer, G.M., \& Sutcliffe, K.M. (2007). Thriving in organizations. In Nelson, D.L \& Cooper, C.L. Positive Organizational Behavior (pp. 74). Sage Publications.

Steger, M.F., Dik, B.J., \& Duffy, R.D. (2012). Measuring meaningful work: The work and meaning inventory (WAMI). Journal of Career Assessmnet, 1-16.

Vuori, T., San, E., \& Kira, M. (2012). Meaningfulness-making at work. Qualitative Research in Organizations and Management: An International Journal, 7 (2), 231-248.

Walt, F. (2018). Workplace spirituality, work engagement and thriving at work. SA Journal of Industrial Psychology, 1-10.

Wambugu, L.W. (2014). Effects of organizational culture on employee performance (Case study of Wartsila Kipevu Ii Power Plant). European Journal of Business and Management, 6 (32), 80-92.

Watson, G.W., Papamarcos, S. D., Teaguw, B.T., \& Bean, C. (2004). Exploring the dynamics of business values: A self-affirmation perspective. Journal of Business Ethics, 49, 337 346. 
Volume 3 Issue 8 (March 2021) PP. 01-12 DOI: 10.35631/IJPPSW.38001

Wolumbwa, F.O., Muchiri, M.K., Misati, E., Wu, C., \& Meliani, M. (2017). Inspired to perform: A multilevel investigation of antecedents and consequences of thriving at work. Journal of Organizational Behavior, 1-13.

Zhai, Q., Wang, S., \& Weadon, H. (2017). Thriving at work as a mediator of the relationship between workplace support and life satisfaction. Journal of Management and Organization, 1-17.

Zhang, X., Austin, S., Glass, J., \& Mills, G. (2008). Toward collective organizational values: A case study in UK construction. Construction Management and Economics, 26 (10), 1009-1028. 